\section{HLA in relation to retinopathy, residual $\beta$-cell function and age at onset in Type 1 (insulin-dependent) diabetic patients}

Sir,

The possible role of genetic factors in the pathogenesis of microangiopathy was recently reviewed in Diabetologia by Barbosa and Saner [1] who pointed out that most studies on Type 1 diabetic patients tend to show an increased frequency of $\mathrm{HLA}-\mathrm{B}_{15}$ or $-\mathrm{DR}_{4}$ in association with severe or proliferative retinopathy. However, as discussed by these authors [1], one Icelandic study [2] has suggested that HLA- $\mathbf{B}_{15}$ positive patients might be less prone to develop retinopathy. This issue may be further elucidated by a recent report by Hoogwerf et al. [3] which demonstrates a decline of C-peptide secretion in Type 1 diabetic patients with increased duration of the disease. In addition, the stimulated $C$ peptide response was found to be less marked in patients who were younger than 10 years old at the onset of diabetes. Furthermore, HLA-DR 4 positive subjects had higher mean C-peptide values than - $-\mathrm{DR}_{4}$ negative patients, irrespective of the duration of the disease. The authors concluded that $\mathrm{DR}_{4}$ positive patients might be blessed by a better preservation of $\beta$-cell function and discussed that this might further glycaemic control, and hence delay or postpone microvascular complications in the diabetic patient [4]. A previous study of the Icelandic Type 1 diabetic population [5] has demonstrated that a subgroup of patients without retinopathy after a diabetes duration of 20 years or more required significantly less insulin than those with retinopathy after a comparable duration of the disease. The mean $( \pm S D)$ age at diagnosis of diabetes in the retinopathy-free subjects was $30 \pm 4$ years and $70 \%$ were females. Late onset of diabetes and female preponderance are believed to characterize "autoimmune" diabetes [6]. In a study of Type 1 diabetic patients with thyroid disorders in Iceland [7] the age at the onset of diabetes was $38 \pm$ 1 years and $80 \%$ were females. They tended to require less than average insulin doses, eye and kidney complications were reactively rare, and, particularly, a higher frequency was found for HLA-B $\mathbf{B}_{15}$ than $-\mathbf{B}_{8}$ (relative risks 4.2 and 2.3 respectively).

Whether HLA-types are directly related to the age at onset of diabetes is presently controversial. HLA-DR ${ }_{4}$ has been reported to be significantly increased in Type 1 diabetes with age of onset after 40 years [8]. Other authors were unable to find such an association in analysing different subgroups according to their age at onset up to the age at onset of 25 years [9]. Likewise, the frequency of HLA-B ${ }_{15}$ is similar in patients diagnosed 0-19 years old compared to those with an age at onset of above 30 years in the Icelandic diabetic patients (unpublished).

In conclusion, HLA-DR ${ }_{4}$, and probably HLA- ${ }_{15}$, because of the strong linkage disequilibrium between these two, appear to be related to better preservation of residual $\beta$-cell function. This is demonstrated by a greater C-peptide response in HLA-DR 4 positive Type 1 diabetes patients. This may result in better glycaemic control in these patients and retard the development of long-term microvascular complications. These data may thus be compatible with the previous finding of less retinopathy in HLA-B $B_{15}$ positive Type 1 diabetic patients in Iceland.

Yours sincerely

R. Danielsen

\section{References}

1. Barbosa J, Saner B (1984) Do genetic factors play a role in the pathogenesis of diabetic microangiopathy? Diabetologia 27: 487-492

2. Danielsen R, Helgason T, Arnason A, Jónasson F (1982) HLA and retinopathy in Type 1 (insulin-dependent) diabetic patients in Iceland. Diabetologia 22: 297-298 (letters)

3. Hoogwerf BJ, Rich SS, Barbosa J (1985) Meal stimulated C-peptide and insulin antibodies in Type 1 diabetic subjects and their nondiabetic sublings characterized by HLA-DR antigens. Diabetes 34: $440-445$

4. Tchobroutsky G (1978) Relation of diabetic control to development of microvascular complications (Review). Diabetologia 15: 143-152

5. Danielsen R, Helgason T, Jónasson F (1983) Prognostic factors and retinopathy in Type 1 diabetics in Iceland. Acta Med Scand 213: 323-326

6. Bottazzo GF, Cudworth AG, Moul DJ, Doniach D, Festenstein H (1978) Evidence for a primary autoimmune type of diabetes mellitus. Br Med J 2: 1253-1255

7. Danielsen R (1982) Thyroid disorders in type 1 (insulin-dependent) diabetics in Iceland. Icel Med J (Suppl) 15: 27 (Abstract)

8. Pittman WB, Acton RT, Barger BO, Bell DS, Go RCP, Murphy CC, Roseman JM (1982) HLA-A, -B, and -DR associations in type 1 diabetes mellitus with onset after age forty. Diabetes 31: 122-125

9. Wolfe E, Spencer KM, Cudworth AG (1983) The genetic susceptibility to Type 1 (insulin-dependent) diabetes: Analysis of the HLADR association. Diabetologia 24: 224-230

\section{Dr. R. Danielsen}

Department of Clinical Physiology

Haukeland Hospital

University of Bergen

Bergen

Norway

\title{
Errata
}

Diabetologia, Volume 28, Number 6, June 1985

In the table of contents on the front cover, the paper by J.Y.Jeremy, C.S. Thompson, D.P. Mikhailidis and P. Dandona should read: Experimental diabetes mellitus inhibits prostacyclin synthesis by the rat penis: pathological implications.

Diabetologia, Volume 28, Number 6, June 1985, pp. 373-378

M. Bendayan: Alteration in the distribution of Type IV collagen in glomerular basal laminae in diabetic rats as revealed by immunocytochemistry and morphometrical approach.

This paper was received on 13 November 1984 and in revised form on 17 April 1985. The author's full postal address is: Dr. M. Bendayan, Département d'Anatomie, Faculté de Médecine, Université de Montréal, CP 6128, Succ A, Montréal, Quebec H3C 3J7, Canada.

Diabetologia, Volume 28, Number 7, July 1985

Due to a most unfortunate error, the previous version of the Full Instructions to Authors was printed instead of the revised version. Please see this issue for the current Full Instructions to Authors. 